\title{
Erratum to: The Compassionate Side of Neuroscience: Tony Sermone's Undiagnosed Genetic Journey-ADNP Mutation
}

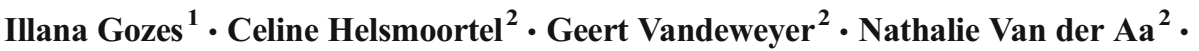 \\ Frank Kooy ${ }^{2} \cdot$ Sandra Bedrosian Sermone ${ }^{3}$
}

Published online: 29 March 2016

(C) Springer Science+Business Media New York 2016

Erratum to: J Mol Neurosci (2015) 56:751-757

DOI 10.1007/s12031-015-0586-6

The original version of this article unfortunately contained mistakes. The changes are as follows:

1. The ADNP mutation should be corrected to:

Results, heterozygous c.1046_1047delTG L349RfsX49

2. Sandra Bedrosian Sermone's affiliation should be updated to "ADNP Foundation, Vancouver, WA, USA". The affiliation section is now updated.

The online version of the original article can be found at http://dx.doi.org/ 10.1007/s12031-015-0586-6.

Illana Gozes

igozes@post.tau.ac.il

$\triangle$ Frank Kooy

frank.kooy@uantwerpen.be

$\triangle$ Sandra Bedrosian Sermone

ADNPfoundation@outlook.com

1 The Lily and Avraham Gildor Chair for the Investigation of Growth Factors, Elton Laboratory for Neuroendocrinology, Department of Human Molecular Genetics and Biochemistry, Sackler Faculty of Medicine, Adams Super Center for Brain Studies and Sagol School for Neuroscience, Tel Aviv University, Tel Aviv, Israel

2 Cognitive Genetics Group, Department of Medical Genetics, University of Antwerp, Antwerp, Belgium

3 ADNP Foundation, Vancouver, WA, USA 